\title{
Solar PV Integrated World Super Grid (WSG): Possibilities, Implementation Issues and Impacts
}

\author{
Ravi Gehlot, Kunal Pardikar, Neeraj Kumar Dasila, and Surajeet Mohanty
}

\begin{abstract}
Solar radiation falling on earth is far more than energy demand of the world, but because of issues related to storage and economics, it is not possible to rely on it, when it comes to fulfill huge electricity demands at national level. A world super grid, connecting all the continents is reported, which is expected to avoid this need of energy storage, while powering the whole world throughout the day by transmitting excess electricity. Feasibility of such grid is determined by matching supply and demand of a particular region. World super grid will be powered by solar photovoltaic panels installed all over the world to facilitate the utilization of solar insolation. At any point of time, Sun shining area will supply electricity to that area itself along with other parts, which are in dark. Electricity demands of regions are analyzed and switching between supplying and demanding regions is modelled according to motion of the sun throughout the day. Several positive impacts of the grid such as environmental, economic and international relations are evaluated. Country preference for such grid is another key issue. Grid preference index is proposed in order to classify countries according to their preference for this grid, considering various factors such as its land area, geographical position and energy security. Policies at national and international level are recommended for smooth implementation of the grid. Elements of this analysis, which can be investigated further to make this rudimentary model more sophisticated are discussed.
\end{abstract}

Index Terms-Grid preference index, power transmission, solar photovoltaic, world super grid.

\section{INTRODUCTION}

Continuously depleting conventional energy sources has been a matter of concern. Researchers have been exploring the possibilities of utilizing alternative resources to fulfil electricity demands. Many countries have already started incorporating renewable energy resources into their electricity mix at micro level. It has been a challenge to extend this incorporation to national level because of varying availability of renewable energy resources throughout the day Storing excess energy and supplying it when needed is possible solution but enormous cost involved undermines its feasibility [1].

Solar energy has highest potential among renewable energy resources to replace conventional energy resources [2]. Availability of solar energy at a particular region depends on the time of the day, geographic location and weather

Manuscript received December 10, 2014; revised January 30, 2015. This work was supported by Department of Energy Science and Engineering, Indian Institute of Technology Bombay, Mumbai, India.

The authors are with the Department of Energy Science and Engineering, Indian Institute of Technology Bombay, Mumbai, India (e-mail: ravi_gehlot@iitb.ac.in). conditions. To eliminate the need of storage, world super grid connecting all the regions is contemplated to supply excess electricity generated in sun shining regions to the regions which are in dark. This grid will be powered by solar photovoltaic panels installed all over the world.

First and foremost task in the feasibility analysis of such grid would be to estimate the land area required in each region for installing solar photovoltaic panels so that it can fulfill demand of regions in dark while powering itself. Throughout the day supplier and consumer regions will continuously revolve according to the motion of the sun. Electricity supply of regions generating power should be matched with total demand of the world on hourly basis. Considering the conversion efficiency of solar photovoltaic panels and peak demand of the world, required land area in supplying region can be estimated on hourly basis.

Feasibility analysis can be further extended to selection of solar photovoltaic technology and type of transmission. Solar photovoltaic technology can be decided by conversion efficiency of commercial PV modules, their cost and their state of commercialization. Transmission losses, which are significant over long distances can be extrapolated from losses present in relatively small networks. Policies will play a crucial role while implementing such global project. Policies enabling technology transfer and financial assistance between the pools of developed and developing countries will ensure smooth implementation of this grid.

Countries will have different preferences for this grid based on various factors like their energy security, location, land area, economy and greenhouse gases emissions. All the factors should be brought together to a uniform index by weighing their relative importance. Grid preference index is proposed and can be used to quantify country's willingness to accept this world super grid.

Replacing conventional energy resources with renewable energy resources would certainly reduce greenhouse gases emissions. Apart from that developing and under developed countries will have guaranteed access to electricity which will provide them an opportunity to overcome existing technical and financial challenges and prosper with international harmony.

\section{MODELLING FrAMEWORK AND ANALYSIS}

\section{A. Feasibility Analysis}

\section{1) Division of world into time zones}

As determining solar insolation throughout the world continuously is fairly complicated, the world is divided into five zones as shown in Fig. 1. Longitudinal width of each zone 
is around $60^{\circ}$ (i.e. $4 \mathrm{hrs}$ ). Thus it is reasonable to assume that during sunshine hours at mean zone longitude, whole zone can generate solar PV electricity.

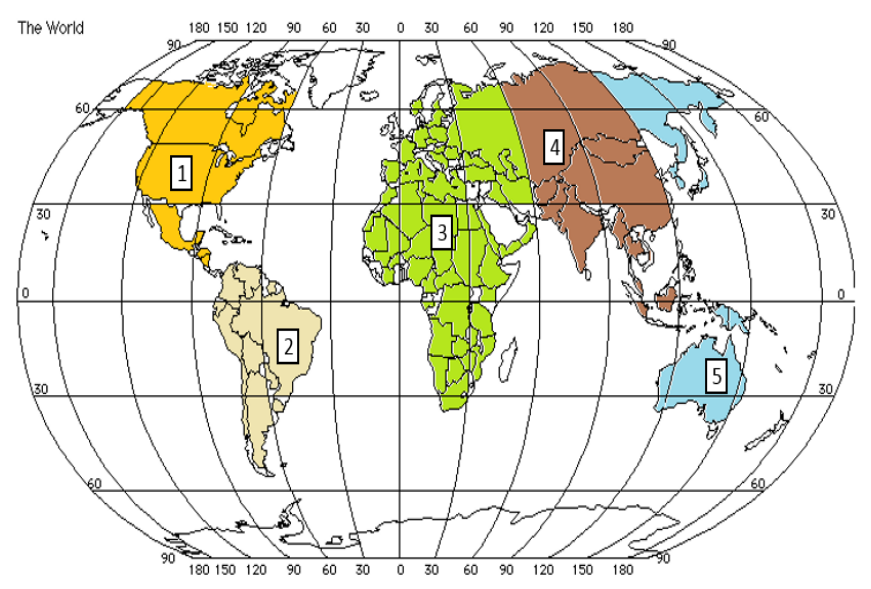

Fig. 1. Division of world.

\section{2) Total land area estimation of each zone}

Land area of each zone is calculated from satellite area calculator, which is corroborated by summing up land areas of countries lying in that particular zone. As PV panels can't be installed on mountains, lakes etc., such areas are excluded from total land area.

3) Electricity generation by solar insolation in each zone

Average daily available solar radiations ( $\mathrm{KWh} / \mathrm{m}^{2}$-day) in different cities are averaged for a zone. Total available solar energy (if all land area is under PV) is obtained by multiplying radiation at unit area with total land area in a particular zone. Considering PV efficiency of $15 \%$ (crystalline silicon) [3], which has matured research and large scale production, total possible electricity generation is calculated, if all land area is used for PV.

\section{4) Role of different zones at each hour}

Assuming eight sunshine hours from 9 AM to 5 PM are constant for all zones; zones generating solar energy are tabulated throughout the day. For example, for first hour (i.e. 00:00 to 01:00) in zone 1, zone 3 and zone 4 are generating electricity through solar PV panels. Hence zones supplying electricity to other zones at any particular hour of the day can be determined from Table I.

TABLE I: THE SUNSHINE HOURS

\begin{tabular}{lllllllllllll}
\hline \hline $\mathbf{Z}$ & \multicolumn{1}{c}{ Hour of the day (00:00-01:00 is denoted as 1 (first hour) and so on.) } \\
\hline $\mathbf{1}$ & 1 & 2 & 3 & 4 & 5 & 6 & 7 & 8 & 9 & 10 & 11 & 12 \\
$\mathbf{2}$ & 5 & 6 & 7 & 8 & 9 & 10 & 11 & 12 & 13 & 14 & 15 & 16 \\
$\mathbf{3}$ & 11 & 12 & 13 & 14 & 15 & 16 & 17 & 18 & 19 & 20 & 21 & 22 \\
$\mathbf{4}$ & 15 & 16 & 17 & 18 & 19 & 20 & 21 & 22 & 23 & 24 & 1 & 2 \\
$\mathbf{5}$ & 19 & 20 & 21 & 22 & 23 & 24 & 1 & 2 & 3 & 4 & 5 & 6 \\
\hline \hline
\end{tabular}

\begin{tabular}{llllllllllllll}
\hline \hline $\mathbf{Z}$ & \multicolumn{1}{l}{ Hour of the day } \\
\hline $\mathbf{1}$ & 13 & 14 & 15 & 16 & 17 & 18 & 19 & 20 & 21 & 22 & 23 & 24 \\
$\mathbf{2}$ & 17 & 18 & 19 & 20 & 21 & 22 & 23 & 24 & 1 & 2 & 3 & 4 \\
$\mathbf{3}$ & 23 & 24 & 1 & 2 & 3 & 4 & 5 & 6 & 7 & 8 & 9 & 10 \\
$\mathbf{4}$ & 3 & 4 & 5 & 6 & 7 & 8 & 9 & 10 & 11 & 12 & 13 & 14 \\
$\mathbf{5}$ & 7 & 8 & 9 & 10 & 11 & 12 & 13 & 14 & 15 & 16 & 17 & 18 \\
\hline \hline
\end{tabular}

Yellow shades represent sunshine in that zone.

\section{5) Electricity demand pattern in each zone}

a) Annual demand

Annual demands of major countries are known. These demands are summed up to calculate annual demands of different zones. It is assumed that electricity demand is uniformly distributed in a country. In case a country like Russia is divided into more than one zone, demand is distributed according to land area of that country in respective zones.

\section{b) Hourly demand}

Considering monthly (Seasonal) and daily load patterns of United States [4] to be applicable for all countries, hourly a demand in different months for all zones is determined. Annual demand is distributed among months according to this monthly load pattern. Monthly demands are further equally divided into daily demands. Using average daily load pattern of mid-working day of the month, demand in each zone at each hour throughout the year is determined.

\section{6) Required PV area in each zone}

Knowing supplier zones at a particular time and total demand at the same time land area required to deploy PV panels in each zone is estimated considering transmission losses as $40 \%$ (explained further). There is a time when every zone except zone 4 supplies power to the whole world single handedly. Demands of each zone are summed up at these timings to estimate demand of the whole world for every day and maximum of these demands is taken into consideration to estimate land area. Considering this maximum demand and transmission losses required maximum supply for that zone is determined. Land area is estimated assuming the conversion efficiency of solar PV panels as $15 \%$.

\section{B. Implementation Issues}

\section{1) Technology for PV panels and transmission lines}

Crystalline photovoltaic panels are considered for this grid, because of having reasonable efficiency (15\%) with matured market for large production. Between two options High Voltage Alternating Current (HVAC) and High Voltage Direct Current (HVDC) lines for long distance transmissions, HVDC transmission is chosen because of relatively less transmission losses as well cost. Another major advantage of HVDC lines is that it overcomes the problem of frequency mismatch among countries. Power can be converted according to respective frequencies of different countries at country level.

Transmission losses increase with length of transmission lines. HVDC and HVAC losses and cost patterns are known for lines of length less than $1600 \mathrm{~km}$, these are further extrapolated for longer distances.

\section{Impacts}

\section{$\mathrm{CO}_{2}$ Emission Reduction}

Total reduction in $\mathrm{CO}_{2}$ emissions is estimated by assuming world's electricity demand is currently fulfilled by coal power plants only and all of them will be replaced by this super grid.

\section{Economic Impacts (Indian Perspective)}

Land area to be used for PV installation in India is estimated by the fraction of land area of India in zone 4. Solar 
PV cost is forecasted up to 2025 using exponential fit of past data. Savings obtained by shutting down conventional coal plants are estimated by fuel cost and operation \& maintenance cost per unit of electricity (Rs./MWh) multiplied by total demand. Fuel cost is considered to be constant assuming technological advancements and inflation rate will nullify each other.

\section{E. Grid Preference Index}

An index proposed to quantize and rank different country's preferences for adopting this super grid. It is understood that preference of a nation will primarily depend on parameters mentioned in Table II.

TABLE II: PARAMETERS FOR GPI

\begin{tabular}{|c|c|c|c|}
\hline No. & Parameter & $\begin{array}{l}\text { Countries having high } \\
\text { preference for grid }\end{array}$ & $\begin{array}{l}\text { Countries having lower } \\
\text { preference for grid }\end{array}$ \\
\hline 1 & Demand & $\begin{array}{l}\text { Having current deficit or } \\
\text { surplus through this grid }\end{array}$ & $\begin{array}{l}\text { Supply-demand are } \\
\text { settled within itself }\end{array}$ \\
\hline 2 & Land Area & Having much land area & Having less land area \\
\hline 3 & Location & $\begin{array}{l}\text { Having position near } \\
\text { equator }\end{array}$ & $\begin{array}{l}\text { Position away from } \\
\text { equator }\end{array}$ \\
\hline 4 & $\begin{array}{l}\text { Coal } \\
\text { Exchange }\end{array}$ & Importing coal & Exporting coal \\
\hline 5 & GDP & Low GDP countries & High GDP countries \\
\hline 6 & $\begin{array}{l}\text { Current } \\
\text { emissions }\end{array}$ & Having high emissions & Having low emissions \\
\hline
\end{tabular}

Analytical hierarchy process (AHP) is used to evaluate weightage for each parameter by comparing parameters in comparison matrix (Refer to Appendix) having consistency 0.03 (very consistent). Table III shows the weightage obtained for parameters.

TABLE III: WEIGHTAGE FOR PARAMETERS

\begin{tabular}{cc}
\hline \hline Parameter & Weightage obtained by AHP \\
\hline Demand (D) & 0.055 \\
Land Area (A) & 0.249 \\
Location (L) & 0.285 \\
Coal exchange (C) & 0.223 \\
GDP (G) & 0.105 \\
Emissions (E) & 0.080 \\
\hline \hline
\end{tabular}

Each country will be given a rank between 1 being lowest preference and 10 being highest preference for the grid considering each parameter at a time. Ranks are further multiplied by weightages. These products are summed up as shown in equation 1, the number which is obtained is termed as 'Grid Preference Index (GPI)'. Maximum possible GPI can be 10 .

Grid Preference Index $(\mathrm{GPI})=$

$R_{d} \times W_{d}+R_{a} \times W_{a}+R_{l} \times W_{l}+R_{c} \times W_{c}+R_{g} \times W_{g}+R_{e} \times W_{e}(1)$

\section{RESULTS}

\section{A. Land Area Required in Each Zone}

Land area under PV installation of each zone is estimated by the maximum demand of the world at times when it is singlehandedly supplying power to the whole world and solar insolation in that zone. Table IV shows percent land area required for $\mathrm{PV}$ installation in each zone.
TABLE IV: PERCENTAGE LAND AREA FOR PV

\begin{tabular}{|c|c|c|c|c|c|c|}
\hline \multirow[t]{2}{*}{$\mathrm{Z}$} & \multirow[t]{2}{*}{$\begin{array}{l}\text { Land } \\
\text { area }\left(10^{6}\right. \\
\left.\mathrm{km}^{2}\right)\end{array}$} & \multirow[t]{2}{*}{$\begin{array}{l}\text { Solar } \\
\text { insolation } \\
\left(\mathrm{KW}-\mathrm{h} / \mathrm{m}^{2}-\mathrm{d}\right. \\
\text { ay) }\end{array}$} & \multirow[t]{2}{*}{$\begin{array}{l}\text { Available } \\
\text { solar } \\
\text { energy } \\
\text { (peta } \\
\text { KWh/yr) }\end{array}$} & \multicolumn{2}{|c|}{$\begin{array}{l}\text { Electricity Maximum } \\
\text { Produced Energy } \\
\text { assuming demand for } \\
\text { all land area peak load } \\
\text { is used (peta (tera }\end{array}$} & \multirow[t]{2}{*}{$\begin{array}{l}\text { Percent } \\
\text { Land } \\
\text { area } \\
\text { required } \\
\text { to fulfill } \\
\text { peak } \\
\text { load }\end{array}$} \\
\hline & & & & $\mathrm{kWh} / \mathrm{yr})$ & KWh/yr) & \\
\hline 1 & 11.59 & 3.90 & 16.49 & 2.75 & 31.18 & 1.26 \\
\hline 2 & 19.15 & 4.03 & 28.18 & 4.23 & 33.24 & 0.79 \\
\hline 3 & 41.73 & 4.12 & 62.75 & 9.41 & 33.81 & 0.36 \\
\hline 4 & 21.20 & 4.39 & 33.94 & 5.09 & 23.14 & 0.45 \\
\hline 5 & 10.80 & 4.04 & 15.91 & 2.39 & 33.35 & 1.40 \\
\hline
\end{tabular}

\section{B. Visualization of Power Transfer}

Fig. 2 shows typical power transfer in a particular zone in a day. During sunshine hours (9AM-5PM) zone generate electricity which is being supplied all over the world while fulfilling its own demand. At hour 14 and 15, generation is highest because this zone is supplying power singlehandedly at these hours.

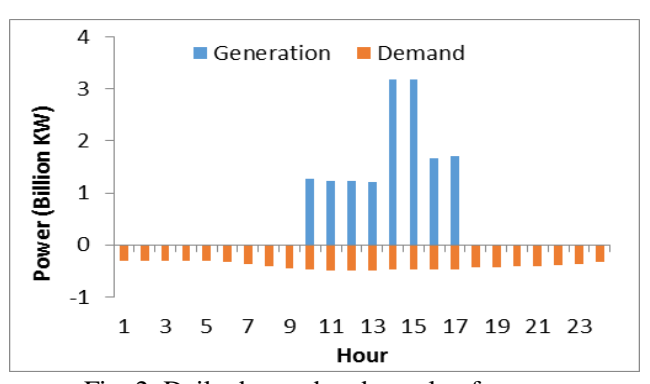

Fig. 2. Daily demand and supply of a zone.

Monthly load profile of zones is depicted in Fig. 3.

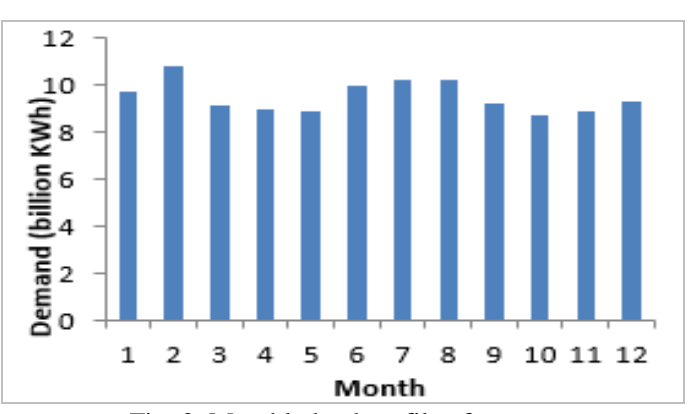

Fig. 3. Monthly load profile of a zone.

Fig. 4 shows power generation and demand pattern of all zones throughout the day.

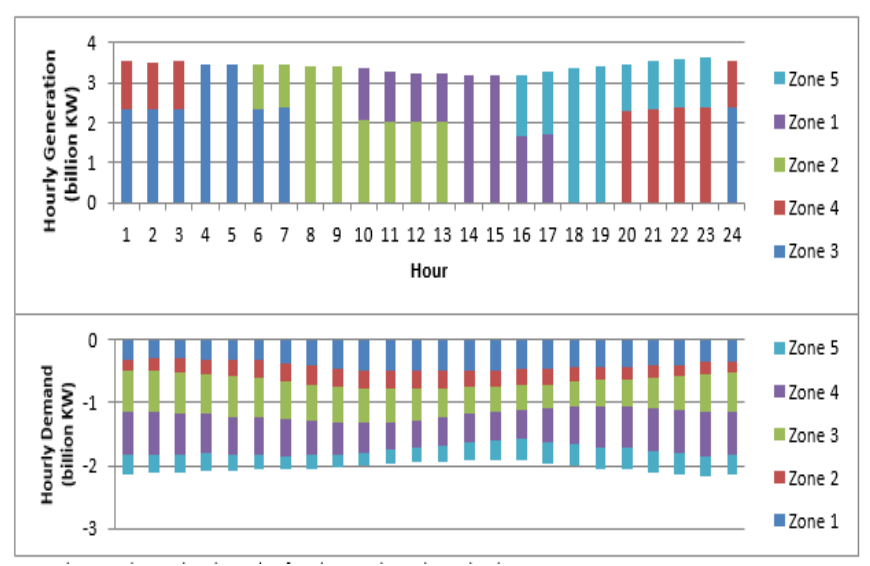

Fig. 4. Demand and supply of each zone throughout the day. 


\section{Transmission Line}

\section{1) Losses}

Losses are estimated as $40 \%$ for HVDC lines by extrapolating following data to $16000 \mathrm{~km}$, which is estimated to be longest line length required in super grid. Losses are very high in case of HVAC lines, which are $100 \%$ for $11000 \mathrm{~km}$. Data used for extrapolation are mentioned in Table $\mathrm{V}[5]$.

TABLE V: TRANSMISSION LOSSES

\begin{tabular}{ccc}
\hline \hline & Percentage Power Loss \\
\hline Length $(\mathrm{km})$ & HVDC $(800 \mathrm{kV})$ & HVAC $(800 \mathrm{kV})$ \\
400 & 3 & 3.5 \\
800 & 4 & 7 \\
1200 & 5 & 10 \\
1600 & 6 & 14 \\
\hline \hline
\end{tabular}

Fig. 5 depicts linear extrapolation of losses in HVAC and HVDC lines.

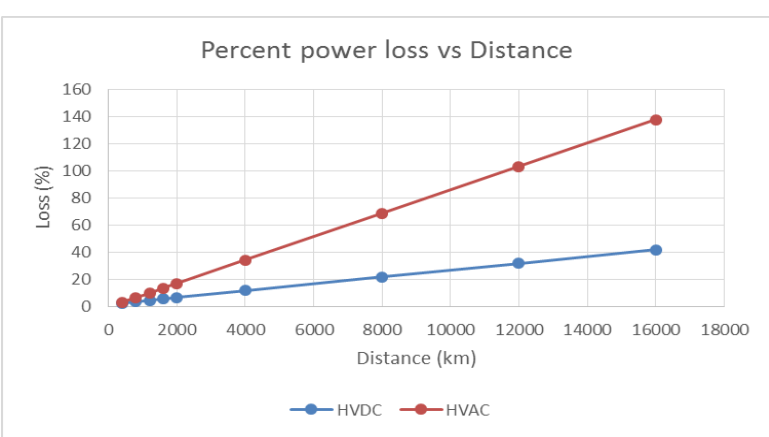

Fig. 5. Transmission losses extrapolation.

\section{2) Cost}

Cost is also taken as deciding factor for type of transmission lines. Following data mentioned in Table VI are extrapolated to estimate cost of longer HVAC and HVDC transmission lines [5].

TABLE VI: TRANSMISSION COST

\begin{tabular}{ccc}
\hline \hline & Cost (in 10 million INR) \\
\hline Length $(\mathrm{km})$ & HVDC $(800 \mathrm{kV})$ & HVAC $(800 \mathrm{kV})$ \\
400 & 10800 & 14800 \\
800 & 14400 & 22800 \\
1200 & 17400 & 33600 \\
1600 & 20400 & 44400 \\
\hline \hline
\end{tabular}

Transmission cost in billion INR is estimated as per linear extrapolation in Fig. 6.

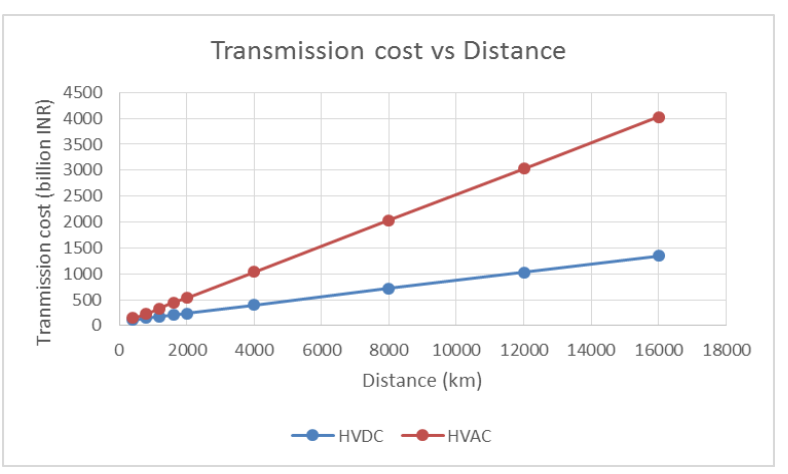

Fig. 6. Transmission cost extrapolation.

\section{D. $\mathrm{CO}_{2}$ Reduction}

For generation of $1 \mathrm{KWh}$ of electricity from coal power plant, average $0.97 \mathrm{Kg}$ of $\mathrm{CO}_{2}$ is emitted [6]. Total $\mathrm{CO}_{2}$ reduction because of replacing all coal power plants can be estimated as $40 \%$ for the total $\mathrm{CO}_{2}$ emissions.

$\mathrm{CO}_{2}$ emission involved in solar PV lifecycle is around $46 \mathrm{gm} / \mathrm{KWh}$ [7]. World's energy demand is approximately 20 peta-Wh. Hence total $\mathrm{CO}_{2}$ emissions of solar PVs are estimated as 920 billion-kg.

Net reduction in $\mathrm{CO}_{2}$ emissions can be calculated as $37 \%$.

\section{E. Economic Analysis (India)}

\section{1) Solar PV cost forecasting}

Fig. 7 depicts exponentially fit of past PV system price data to forecast price, which is to be used in economic analysis for 2025 [8]. Table VII shows forecasted price for coming years.

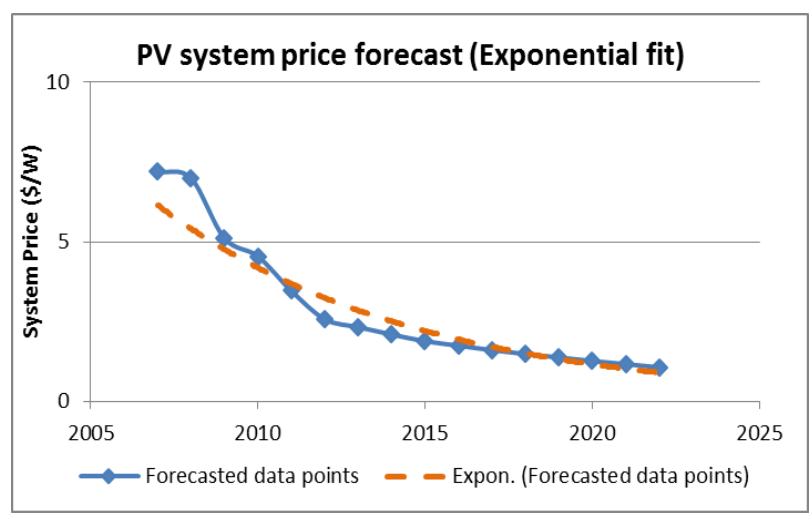

Fig. 7. Solar PV system cost forecasting.

TABLE VII: PV COST FORECASTING

\begin{tabular}{lcccccc}
\hline \hline Year & 2013 & 2015 & 2017 & 2019 & 2020 & 2022 \\
\hline $\begin{array}{l}\text { System } \\
\text { Price }(\$ / W)\end{array}$ & 2.33 & 1.89 & 1.61 & 1.38 & 1.27 & 1.07 \\
\hline \hline
\end{tabular}

\section{2) Payback period and annualized cost}

Table VIII describes pay back analysis of solar PV super grid for India in year 2013 and 2025. Payback period is calculated based on saving from replacing coal plants with solar PV plants and investment in solar PV systems. It is assumed that transmission network cost for India will not be significant as it has already a well-established transmission network.

TABLE VIII: PAYBACK ANALYSIS

\begin{tabular}{ccc} 
TABLE VIII: PAYBACK ANALYSIS & \\
\hline \hline Year & 2013 & 2025 \\
\hline System Price (\$/W) & 2.33 & 0.7 \\
PV installation cost (billion INR) & 57257 & 17201 \\
Coal fuel cost (USD/MWh) & 29.2 & 29.2 \\
Electricity Demand (tera-Wh) & 899 & 1950 \\
Cost of electricity generation from coal & 1575 & 3416 \\
(billion INR) & 36 & 5 \\
Payback Period (years) & & \\
\hline \hline
\end{tabular}

To put investment required in context, Table IX shows annualized investment required to set up PV panels in 2013 and 2025. Discount rate of $10.5 \%$ is used for 40 years to calculate capital recovery factor, which is further used to annualize the investment. 
TABLE IX: ANNUALIZED COST ANALYSIS

\begin{tabular}{ccc}
\hline \multicolumn{3}{c}{ TABLE IX: ANNUALIZED COST ANALYSIS } \\
\hline Year & 2013 & 2025 \\
\hline Capital Recovery Factor (10.5\%, 40 years) & 0.1083 & 0.1083 \\
PV installation cost (in billion INR) & 57257 & 17202 \\
Annualized Investment & 1863 \\
(in billion INR) & 6200 & \\
\hline \hline
\end{tabular}

\section{F. Grid Preference Index}

\section{1) Sample results}

Table X shows ranks given by intuition for each country for different parameters. Rightmost column shows the GPI which is calculated based on ranks and weightages for each parameter.

TABLE X: SAMPLE ANALYSIS FOR GPI

\begin{tabular}{cccccccc}
\hline \hline Country & Demand & $\begin{array}{c}\text { Land } \\
\text { area }\end{array}$ & Location $\begin{array}{c}\text { Coal } \\
\text { exchange }\end{array}$ & GDP & Emissions $\begin{array}{c}\text { Score } \\
/ 10\end{array}$ \\
\hline India & 7 & 8 & 8 & 7 & 5 & 4 & 7.06 \\
Japan & 6 & 3 & 4 & 9 & 2 & 6 & 4.91 \\
Sudan & 6 & 5 & 8 & 5 & 8 & 2 & 5.97 \\
Norway & 4 & 2 & 2 & 4 & 3 & 3 & 2.73 \\
Weightage & 0.055 & 0.249 & 0.285 & 0.223 & 0.105 & 0.089 & \\
\hline \hline
\end{tabular}

\section{POLICY FrAMEWORK}

To achieve this ambitious target, policies are going to play meaningful role. A few points are should be considered while framing policies to implement this super grid.

1) Technology transfer towards gradient - International collaboration for accelerated learning and flow of solar PV and transmission technologies from technically advanced countries to those who are lacking.

2) Financial model for implementation - An international organization like International Monetary Fund (IMF) should be there to monitor and control funds in order to implement such a huge investment. There should be provision of loans for under developed countries.

3) Trade of electricity - It is expected that not all the countries will contribute with their land (which is nearly $0.1 \%$ of total land) to deploy solar panels. They might not have that much land for panels or they might have other preferences to use their land. In those cases electricity has to be imported from other countries. Countries like India, Russia having huge land area will prefer to have more generation than their own demand. They can have economic trade for excess generated electricity, with the countries are having less generation.

4) R\&D collaborations - To support continuing technology development and sustained $R \& D$ efforts to advance the cost and efficiency improvements in both power generation and transmission.

5) Infrastructure - In order to fulfill huge requirements of solar panels, governments will be required to foster PV and transmission cables manufacturing businesses. Nations will have to be create policies frameworks for market deployment, including tailored incentive schemes to accelerate market competitiveness.

6) Policies for transition from conventional transmission to super grid - It is obvious that sudden change is not possible. Policies have to be there to promote PV systems incorporated into existing grids initially. Reliability and ability to deliver power will have to be optimized at certain stages and network should be increased on iterative basis. Nations should start from ground level like targeting villages, towns, cities, states and then nation as a whole.

\section{INSIGHTS}

Land area percentages show a significant variation among different zones. Zone 1 has highest percent required because of zone 1 has least area, while zone 4 has least percent because it can be seen that there is no time when zone 4 is delivering power single handedly.

Power transfer among different zones at each hour can be visualized by column charts given in Fig. 4. Since supply has to overcome transmission losses, difference between heights of demand and supply can be observed. It can be known at any hour in any month, which zone is delivering power to which other zones.

In economic analysis for India, payback period is calculated taking annual saving in electricity generation into account. Payback period is 36 years if we implement this grid now and the same is 5 years if it is implemented a few years later.

Annualized cost of the whole investment 6200 billion INR, it comes out to be close to $6 \%$ of current GDP of India. Annual cost is also realized as a reasonable number observing India's current budget expenditure.

\section{LIMITATIONS}

\section{A. Division of World in 5 Discrete Zones}

Such model assumes that at a particular time solar radiation in whole zone is same. This causes situations when only one zone is supplying electricity to whole world, causing large area to be covered under PV installations. In reality, at any time some part of the zone may generate electricity when the mean longitude of that zone is dark.

\section{B. Constant Load Profiles for All Zones}

For calculation of monthly electricity distribution, load profile of United States is used for all zones. As load profiles depend on country type (developed or developing), culture, location etc. this assumption limits the scope of analysis done to estimate hourly demands. For hourly electricity distribution, mid working day of each month is chosen to calculate hourly demands, which cannot be the case all the time.

As analysis for each hour in a year is done, load profile for different zones can be obtained and similar analysis can be done easily by just changing their loads in each month and each hour.

\section{Demand Proportional to Land Area}

Total electricity demand is distributed according to land area in different zones. This is a very crude assumption as electricity demands vary largely as we move from cities to deserts. 
Population density, industrial density etc. parameters can be chosen to distribute total electricity demand, to get actual demands in different zones.

\section{Sunshine Hours Constant for Each Zone}

Average sunshine hours at any place depend on the location of the place relative to equator. Sunshine hours vary seasonally. The effect of cloudy weather or shading is not taken into account. These factors also should be taken into account for more sophisticated model.

\section{E. Constant Coal Fuel Price}

Coal prices will change with time as it is an exhaustible energy source. No extent of technological developments can keep the coal price constant.

\section{F. Transmission Line Losses Constant at $40 \%$}

Transmission losses will depend on the distance between two grids. This is a worst case assumption which overestimates the requirement of PV area than actually required.

\section{G. Linear Relation between Losses, Cost of Transmission Lines vs. Distance}

For calculation of total cost of transmission lines, linear relation between cost and length of the line is assumed. Actual economics of these lines can be realized and proper formulated extrapolation can be done.

\section{USEFULNESS OF THE PAPER}

From the analysis done it is evident that such a world super grid is possible. Maximum percentage of land area under PV panels is around $1.4 \%$ of total land area, which is viable.

Payback period of PV system installation will reduce up to 5 years in 2025 . This seems to be a very attractive proposal with benefits including development of economy, increased literacy rate etc.

The grid preference index (GPI) model will be very useful to determine the willingness of any country to participate in such a grid. If the GPI of a country is low, some policy may be formulated to give incentives to that particular country.

This paper is targeted to policy makers also, to assist them to take steps towards renewable energy resources. Engineers can also have insights into several technologies available to extract electricity from solar sources and technical issues related to it like transmission, stability etc.

Meaningful exchanges of electricity and technologies among different countries, will lead to unify them in terms of economy and international harmony.

\section{APPENDIX}

\section{Weightage for Different Parameters of GPI}

Steps for finding weightages for different parameters

1) All possible parameters are compared in a comparison matrix
2) Comparison number between each two parameters is assigned by intuitions

3) Upper triangular matrix is simply inverse of corresponding number in lower triangular matrix

4) Eigen values and eigen vector matrix are calculated for this matrix

5) Maximum among all eigen number and corresponding eigen vector are chosen

6) All elements of that eigen (column) matrix are divided by their total so as to get weightages of respective parameters.

\section{ACKNOWLEDGMENT}

We would like to acknowledge Professor Rangan Banerjee from Department of Energy Science and Engineering, Indian Institute of Technology Bombay for guiding us throughout.

\section{REFERENCES}

[1] Solar Energy Perspectives: Executive Summary, International Energy Agency, 2011.

[2] D. Ton, "Solar energy grid integration systems - Energy storage (SEGIS-ES)," US Department of Energy, 2008.

[3] Y. Chu, "Review and comparison of different solar energy technologies," Global Energy Network Institute, 2011.

[4] M. Bahrman, "WECC transmission planning seminar," ABB Grid Systems, 2009.

[5] How much carbon dioxide is produced per kilowatthour when generating electricity with fossil fuels? US Energy Information Administration. [Online]. Available: http://www.eia.gov/tools/faqs/faq.cfm?id=74\&t=11.

[6] W. Moomaw, P. Burgherr, G. Heath, M. Lenzen, J. Nyboer, and A. Verbruggen, "Special report on renewable energy sources and climate change mitigation," IPCC, 2011.

[7] National grid US. National Grid. [Online]. Available: http://www.nationalgridus.com/.

[8] P. Ron, W. Clint, and W. Trevor, Clean Energy Trends, March 2013.

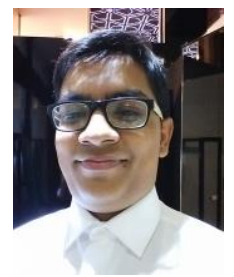

Ravi Gehlot is pursuing his master's degree in energy systems engineering after completing his bachelor's degree in energy science and engineering from Indian Institute of Technology Bombay, Mumbai, Maharashtra, India. He was born in Jodhpur, Rajasthan, India on December $17^{\text {th }} 1991$.

He worked as a summer intern at R\&D division of Tanaka Holdings in Tsukuba, Japan where he optimized components of dye sensitized solar cell with fast dyeing. As a research associate at University of Illinois Urbana Champaign, he worked with professor Uddin from nuclear, Plasma and Radiological Engineering Department. He forecasted different energy resources for 2050 for India.

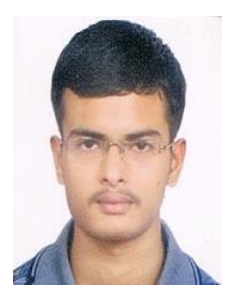

Kunal Pardikar is pursuing his master's degree in fluid and thermal sciences after completing bachelor's degree in energy science \& engineering from IIT Bombay, Mumbai, India. He was born at Nanded, Maharashtra, India on August 15, 1992.

He has worked with Robert Bosch Engineering \& Business Solutions (RBEI), Bangalore as an intern. He has worked on 'Efficiency improvement of domestic gas fired water heater' during this internship. 